\title{
Activity of selected components of antioxidant system in grass pea and yellow lupine protoplasts after enzymatic isolation
}

\author{
Alina Wiszniewska *, Barbara PiwowarczyK \\ Institute of Plant Biology and Biotechnology, Faculty of Biotechnology and Horticulture, \\ University of Agriculture in Krakow, Kraków, Poland
}

\begin{abstract}
In this study, the performance of the antioxidant system in protoplasts of grass pea (Lathyrus sativus L.) and yellow lupine (Lupinus luteus L.) isolated using solutions of different compositions was evaluated. Protoplasts were isolated from leaves of grass pea and cotyledons of yellow lupine seedlings grown in vitro. Hydrolytic enzymes were dissolved in three different solutions (ultrapure water, inorganic salt solution (CPW), and inorganic salt solution with organic additives $(\mathrm{C})$ ). Protoplasts purified using these solutions were subjected to the analyses of peroxidase (POD) and radical scavenging activities. Phenolic profile was also determined. In grass pea, the highest POD was determined in protoplasts isolated in CPW salt solution, while in yellow lupine, the other two solutions were found superior. Protoplasts isolated in CPW salt solution had the highest content of phenolic compounds, ranging from 28.8 to 40.1 and from 32.0 to $58.0 \mathrm{mg} / \mathrm{g}$ fresh weight (f.w.) in lupine and grass pea, respectively. Moreover, in protoplasts obtained using CPW solution, the total antioxidant activity was the highest in all tested genotypes as expressed by high proportion of scavenged 2,2,-diphenyl-1-picrylhydrazyl (DPPH) radical. The results showed that changes in composition of the isolation solutions affected the level and activity of selected components belonging to cell antioxidant system in legume protoplasts. Considering the recalcitrance of two studied plants in protoplast culture, this finding is an important piece of information because events occurring at the stage of isolation may affect further development of protoplasts in the culture.
\end{abstract}

Key words: Lathyrus sativus L., Lupinus luteus L., peroxidase, phenolic compounds, radical scavenging activity, oxidative stress

\section{Introduction}

During the isolation process, protoplasts encounter serious stress conditions. The quality of isolated protoplasts is therefore significantly affected by the isolation itself, and isolation is considered to have a far more important impact on the culture viability than the composition of the culture medium (Hahne and Lortz, 1988; Meyer et al., 1993). The process of protoplast enzymatic isolation is associated with the release of phytotoxic factors from digested cell walls, as well as with alterations in oxygen balance within the cell (Ishii, 1987; Hahne and Lortz, 1988). It is believed that the homeostatic mechanisms of oxygen metabolism may not be maintained resulting in the overproduction of active forms of oxygen
(Roubelakis-Angelakis, 1993). Reactive oxygen species (ROS) play a crucial role in plant morphogenesis and development, acting as signaling molecules at the level of both the plant cell and the whole organism (Jones and Smirnoff, 2005), and therefore may be involved in determining the regeneration ability of the protoplasts. Studies on non-regenerating and regenerating protoplasts revealed that increasing accumulation of toxic oxygen during isolation is likely to cause protoplast recalcitrance (Sinimis et al., 1994; Papadakis et al., 2002; Xu et al., 2013). It has also been shown in protoplasts of barley that a failure of an antioxidative defense mechanism is associated low cell viability and mitotic arrest (Kapur et al., 1993).

\footnotetext{
* Corresponding author: Institute of Plant Biology and Biotechnology, Faculty of Biotechnology and Horticulture, University of Agriculture in Krakow, Al. 29 Listopada 54, 31-425, Kraków, Poland; e-mail: a.wiszniewska@ogr.ur.krakow.pl
} 
Recalcitrance is an important problem in in vitro manipulations on lupines and grass pea (Święcicki et al., 2000 , Ochatt et al., 2001). In protoplast cultures of largeseeded (grain) legumes, a lack of proliferation or a lack of morphogenic response is often observed (Babaoglu, 2000; Ochatt et al., 2001; Pratap et al., 2010). On the contrary, a screening for responsive genotypes and donor explants allowed to achieve a considerable progress in protoplast regeneration in numerous genera of small-seeded legumes (mainly forage legumes), such as Astragalus (Hou and Jia, 2004), Medicago (Zafar et al., 1995), and Trifolium (Rybczyński, 1997). According to Święcicki et al. (2000), for lupines, there are a few interesting examples of development of somatic hybrids exhibiting desirable agricultural features. Also in grass pea, the stimulation of mitoses and cluster formation was achieved after an intergeneric fusion with pea protoplasts (Durieu and Ochatt, 2000). Some recent reports have indicated that the recalcitrance in protoplast culture of several lupine species could be partially bypassed using various cultural manipulations, chemical nursing, selection of donor plants and explants (Schafer-Menuhr, 1991; Sinha and Caligari, 2009, Sonntag et al., 2009, Wiszniewska and Pindel, 2009). However, in grass pea and yellow lupine, early stages of the protoplast culture are often accompanied by disturbances in cell wall reconstitution, arrested divisions, and decreasing viability (Wiszniewska et al., 2012; Wiszniewska and Piwowarczyk, 2014). Reasons preventing these protoplasts from expressing totipotency are stil undefined. The limited regenerating ability may be a result of oxidative damage and ineffective antioxidant defense in isolated protoplasts. However, the role of oxidative stress generated at the stage of isolation in relation to the recalcitrance of grass pea and yellow lupine protoplasts has not been elucidated to date.

Therefore, we evaluated the performance of selected components of the cell antioxidant system in freshly isolated protoplasts of grass pea (Lathyrus sativus L.) and yellow lupine (Lupinus luteus L.). The total antioxidant activity, the activity of peroxidase (POD), and the content of phenolic compounds were determined. The effect of various compositions of solutions used for the isolation on the level and activity of cell antioxidant system was discussed in relation to protoplast recalcitrance. This is the first report presenting the antioxidant response to the isolation conditions of Lathyrus and Lupinus protoplasts.

\section{Materials and methods}

\section{Plant material}

Two species of grain legumes, namely, grass pea ( $\mathrm{La}-$ thyrus sativus L.) and yellow lupine (Lupinus luteus L.) were used as plant material. For each species, the following two cultivars were tested: 1) grass pea "Derek" and "Krab" and 2) yellow lupine "Lord" and "Taper."

\section{Protoplast isolation}

Protoplasts were isolated from in vitro seedlings. Sterilized seeds were cultivated on an agar-solidified medium composed of MS salts (Murashige and Skoog, 1962) and $2 \%$ sucrose. Seeds were kept in light $\left(80 \mu \mathrm{mol} / \mathrm{m}^{2} / \mathrm{s}\right.$ irradiance and 16 -h photoperiod) at $24 \pm 2{ }^{\circ} \mathrm{C}$. Grass pea protoplasts were isolated from leaves of three-week-old seedlings, while yellow lupine protoplasts were isolated from cotyledons of two-week-old seedlings. Grass pea leaves, without lower epidermis, were incubated overnight in enzymatic mixture containing $1 \%$ Cellulase Onozuka R-10 (Kinki Yakult Co. Ltd., Nishinomiya, Japan), 0.5\% Macerozyme Onozuka R-10 (Kinki Yakult Co. Ltd., Nishinomiya, Japan), and $11 \%$ sorbitol as osmotic stabilizer. Yellow lupine cotyledons, finely sliced, were incubated for $4 \mathrm{~h}$ on a gyratory shaker $(80 \mathrm{rpm})$ in enzyme consisting of 2\% Cellulase Onozuka R-10, 1\% Pectinase (Sigma Chemical Co., St. Louis, MO, USA), and 14\% sorbitol. Three types of solutions/solvents were used to prepare enzymatic mixtures as follows: 1) MQ-ultrapure water (Millipore Direct system Q3); 2) C solution (according to Babaoglu, 2000, modified by Sonntag et al., 2009); and 3) cell and protoplast washing (CPW) salt solution (Frearson et al., 1973) with 0.1\% MES [2-(N-morpholino) ethanesulfonic acid] buffer (Table 1). Protoplasts were separated from undigested tissues by filtration through a $100-\mu \mathrm{m}$ nylon-mesh filter. The protoplast suspension was centrifuged at $168 \mathrm{~g}$ for $5 \mathrm{~min}$. The precipitate was dissolved in $8 \mathrm{ml}$ of sucrose solution with addition of MES buffer, overlaid with $1 \mathrm{ml}$ of W5 medium (Menczel et al., 1981), and centrifuged at $242 \mathrm{~g}$ for $10 \mathrm{~min}$. Viable protoplasts (mean viability $>90 \%$ ), visible as a ring on the border of the two solutions, were collected and re-suspended in appropriate sorbitol solution prior to further analyses.

\section{Assessment of antioxidant parameters}

Phenolic compounds. According to Fukumoto and Mazza (2000), the content of total phenols, as well as cinnamic acid derivatives, flavonols, and anthocyanins 
Table 1. Composition of enzyme solutions

\begin{tabular}{c|c|c}
\hline \multicolumn{3}{c}{ Solution $^{\#}$} \\
\hline $\mathrm{MQ}^{\mathrm{a}}$ & $\mathrm{C}^{\mathrm{b}}[\mathrm{mg} / \mathrm{l}]$ & $\mathrm{CPW}^{\mathrm{c}}[\mathrm{mg} / \mathrm{l}]$ \\
\hline & $1480 \mathrm{CaCl}_{2} \cdot 2 \mathrm{H}_{2} \mathrm{O}$ & $150 \mathrm{CaCl}_{2}$ \\
Ultrapure water & $100 \mathrm{NaH}_{2} \mathrm{PO}_{4} \cdot 2 \mathrm{H}_{2} \mathrm{O}$ & $250 \mathrm{MgSO}_{4}$ \\
& $100 \mathrm{KNO}_{3}$ & $2.5 \mathrm{Fe}_{2}\left(\mathrm{SO}_{4}\right)_{3} \cdot 6 \mathrm{H}_{2} \mathrm{O}$ \\
& $1000 \mathrm{Casamino}$ & $0.16 \mathrm{KI}$ \\
& $10000 \mathrm{PVP}$ & $0.00025 \mathrm{CuSO}_{4}$ \\
& $1000 \mathrm{MES}$ & $1000 \mathrm{MES}$ \\
\hline
\end{tabular}

\#All enzyme solutions contained: 1\% Cellulase Onozuka R-10, 0.5\% Macerozyme Onozuka R-10, 11\% sorbitol for Lathyrus, 2\% Cellulase Onozuka R-10, 1\% Pectinase, $14 \%$ sorbitol for Lupinus, ${ }^{a}$ Millipore Direct system Q3; ${ }^{b}$ according to Babaoglu (2000) modified by Sonntag et al. (2009); ${ }^{\mathrm{c}}$ according to Frearson et al. (1973)

was determined using the spectrophotometric method. Centrifuged protoplasts were poured over $1 \mathrm{ml}$ of $80 \%$ methanol and shaken. The extract $(0.1 \mathrm{ml})$ was mixed with $0.1 \mathrm{ml} 0.1 \% \mathrm{HCl}$ solution in $96 \%$ ethanol and then $1.8 \mathrm{ml} 2 \% \mathrm{HCl}$ was added. After $15 \mathrm{~min}$, the absorbance was measured at wavelengths of $280,320,360$, and $520 \mathrm{~nm}$. Using calibration curves made for chlorogenic acid, caffeic acid, quercetin, and cyanidin, the content of total phenols, cinnamic acid derivatives, flavonols, and anthocyanins was calculated. The content of phenolic compounds was provided in milligram expressed per $1 \mathrm{~g}$ of protoplasts.

POD activity. According to Lück (1962), the activity of the enzyme was determined by a spectrophotometric method (Hitachi U-2900 Double Beam spectrophotometer). The protoplast suspension was shaken in $1.5 \mathrm{ml}$ of phosphate buffer ( $\mathrm{pH}$ 6.2). The extract $(1 \mathrm{ml})$ was mixed with phosphate buffer $(1 \mathrm{ml}), 0.1 \mathrm{ml} 1 \%$ solution of p-phenylenediamine, and $0.1 \mathrm{ml} 0.1 \%$ hydrogen peroxide $\left(\mathrm{H}_{2} \mathrm{O}_{2}\right)$. p-Phenylenediamine was oxidized by POD to colored phenazine. The absorbance of the reaction product was measured at $485 \mathrm{~nm}$ at 1 and 2 min after the addition of $\mathrm{H}_{2} \mathrm{O}_{2}$. One unit of POD activity (U) corresponds to an absorbance increase of 0.1 . The POD activity was expressed as the number of units per minute per $1 \mathrm{~g}$ of protoplasts.

Radical scavenging activity. A stable free radical DPPH (2,2,-diphenyl-1-picrylhydrazyl) was used to test the radical scavenging activity of protoplast extracts (Pekkarinen et al., 1999). The changes in the absorbance of the DPPH solution, following the reduction of $\mathrm{DPPH}$, were measured at $517 \mathrm{~nm}$. For the analysis, the same $80 \%$ methanol extracts were used as for the phenolic compound analysis (see above). In samples containing $1.8 \mathrm{ml} 0.1 \mathrm{mM}$ DPPH solution in $96 \%$ ethanol and $0.2 \mathrm{ml}$ of protoplast extracts, a decreasing absorbance of the DPPH solution was detected after $30 \mathrm{~min}$. The antioxidant activity of extracts was expressed in milligram of reduced DPPH per $1 \mathrm{~g}$ of protoplasts, based on the method described by Augustynowicz et al. (2014).

\section{Statistical analyses}

All analyses were made in four replications. The significant differences between arithmetic means of total phenolic content, cinnamic acid derivative content, flavonol content, anthocyanin content, POD activity, and scavenging activity were determined using Tukey's test at $P<0.05$. Statistica 9.0 software (StatSoft Inc. Tulsa, OK, USA) was used to conduct statistical analyses.

\section{Results}

The applied procedure of protoplast isolation, especially the type and concentration of cellulolytic and pectinolytic enzymes, as well as efficient purification, assured a high yield of protoplasts that were next subjected to biochemical analyses. The kind of solution used for enzymatic mixtures did not influence protoplast viability and yield (data not presented). In contrast, in the examined components of the protoplast antioxidant system, significant differences occurred between tested solutions.

Phenolic compounds. In both species, the highest content of total phenols was found in protoplasts isolated in CPW salt solution (Table 2); it ranged from 28.8 to 
Table 2. The effect of solution type on total content of phenols, cinnamic acid derivatives, flavonols, and anthocyanins (mg/g f.w.) in grass pea and yellow lupine protoplasts

\begin{tabular}{|c|c|c|c|c|c|}
\hline \multirow{2}{*}{$\begin{array}{c}\text { Traits }^{*} \\
{[\mathrm{mg} / \mathrm{g} \text { f.w. }] \pm \mathrm{SD}}\end{array}$} & \multirow{2}{*}{$\begin{array}{c}\text { Type } \\
\text { of solution }\end{array}$} & \multicolumn{2}{|c|}{ Grass pea } & \multicolumn{2}{|c|}{ Yellow lupine } \\
\hline & & Derek & Krab & Lord & Taper \\
\hline \multirow{3}{*}{ Total phenols } & MQ & $4.1 \pm 0.5 \boldsymbol{e}$ & $8.3 \pm 0.5 \boldsymbol{d}$ & $9.1 \pm 0.2 \quad c$ & $9.7 \pm 2.3 c$ \\
\hline & $\mathrm{C}$ & $17.4 \pm 0.1 \quad c$ & $18.5 \pm 0.7 c$ & $6.3 \pm 1.7 c$ & $6.6 \pm 0.8 c$ \\
\hline & $\mathrm{CPW}$ & $58.2 \pm 1.5 \mathrm{a}$ & $32.0 \pm 2.1 \quad b$ & $28.8 \pm 4.4 \quad \boldsymbol{b}$ & $40.1 \pm 9.3 a$ \\
\hline \multirow{3}{*}{$\begin{array}{l}\text { Cinnamic acid } \\
\text { derivatives }\end{array}$} & MQ & $0.7 \pm 0.1 \boldsymbol{e}$ & $2.0 \pm 0.1 d$ & $2.0 \pm 0.1 c$ & $1.4 \pm 0.6 c$ \\
\hline & $\mathrm{C}$ & $3.9 \pm 0.1 c$ & $4.2 \pm 0.2 c$ & $1.4 \pm 0.4 c$ & $2.3 \pm 0.2 \quad c$ \\
\hline & CPW & $13.4 \pm 0.4 \boldsymbol{a}$ & $7.3 \pm 0.4 \quad b$ & $5.5 \pm 0.7 \quad b$ & $9.3 \pm 2.1 \quad \boldsymbol{a}$ \\
\hline \multirow{3}{*}{ Flavonols } & MQ & $1.0 \pm 0.3 e$ & $2.9 \pm 0.2 \boldsymbol{d}$ & $2.6 \pm 0.1 c$ & $3.2 \pm 1.0 \quad c$ \\
\hline & $\mathrm{C}$ & $5.5 \pm 0.1 c$ & $6.0 \pm 0.2 c$ & $1.8 \pm 0.5 c$ & $1.7 \pm 0.2 c$ \\
\hline & $\mathrm{CPW}$ & $19.3 \pm 0.6 \boldsymbol{a}$ & $10.6 \pm 0.6 \quad b$ & $7.9 \pm 0.9 \quad b$ & $13.7 \pm 3.6 a$ \\
\hline \multirow{3}{*}{ Anthocyanins } & $\mathrm{MQ}$ & $0.2 \pm 0.0 \boldsymbol{e}$ & $1.3 \pm 0.1 d$ & $0.8 \pm 0.1 c$ & $1.4 \pm 0.6 c$ \\
\hline & $\mathrm{C}$ & $2.8 \pm 0.0 \quad c$ & $3.1 \pm 0.1 c$ & $0.6 \pm 0.2 c$ & $0.4 \pm 0.1 \quad c$ \\
\hline & $\mathrm{CPW}$ & $9.8 \pm 0.3 \quad \boldsymbol{a}$ & $5.4 \pm 0.3 \quad b$ & $4.2 \pm 0.4 \quad \boldsymbol{b}$ & $6.8 \pm 1.4 \quad a$ \\
\hline
\end{tabular}

* different letters - significant difference at $P \leq 0.05$ within one species and trait

40.1 and from 32.0 to $58.0 \mathrm{mg} / \mathrm{g}$ f.w. in lupine and grass pea, respectively. In comparison, in protoplast isolated in two other solutions, the level of phenolics was significantly lower (6.3-9.7 and 4.1-18.5 mg/g f.w. in lupine and grass pea, respectively). In lupine, there were no differences between ultrapure water and $\mathrm{C}$ solution. In grass pea, the lowest level of phenolics was determined in protoplasts isolated in ultrapure water (Table 2). Considering the examined groups of phenolic compounds, i.e., cinnamic acid derivatives (phenolic acids), flavonols, and anthocyanins, similar tendencies were observed (Table 2). In all cases, protoplasts isolated in $\mathrm{CPW}$ salt solution had the highest content of respective compounds. Lupine cultivars responded uniformly to isolation in solution $\mathrm{C}$ and ultrapure water. In grass pea, protoplasts had a higher content of respective phenolics after isolation in $\mathrm{C}$ solution than in pure water.

Differences in the level of phenolic compounds between the studied genotypes of lupine and grass pea were found. Comparing lupine cultivars, a higher content of total phenols and respective groups of phenolic compounds was determined in "Taper" protoplasts isolated in CPW salt solution (Table 2). In grass pea, protoplasts of "Derek" contained more phenolics after isolation in CPW salt solution, while "Krab" had a higher content of phenolic compounds after isolation in ultrapure water (Table 2).
POD activity. The activity of POD in yellow lupine protoplasts was significantly higher than in grass pea; it ranged from 14.5 to 38.8 and from 3.2 to $17.0 \mathrm{U} / \mathrm{min} / \mathrm{g}$ f.w. in lupine and grass pea, respectively. In grass pea, the highest POD activity was determined in protoplasts isolated in CPW salt solution, amounting to 17.0 and $13.4 \mathrm{U} / \mathrm{min} / \mathrm{g}$ f.w. in "Krab" and "Derek," respectively (Fig. 1). Enzyme activity in the remaining isolation solution did not exceed 9 and $5 \mathrm{U} / \mathrm{min} / \mathrm{g}$ f.w. in "Krab" and "Derek," respectively. In lupine protoplasts, the activity of POD differed between genotypes and applied solutions. The highest values were detected in "Lord" protoplasts isolated in ultrapure water $(34.4 \mathrm{U} / \mathrm{min} / \mathrm{g}$ f.w.) and in "Taper" protoplasts isolated in C solution $(38.8 \mathrm{U} / \mathrm{min} / \mathrm{g}$ f.w.), while the lowest in "Lord" protoplasts isolated in CPW salt solution (14.5 U/min/g f.w.) and in "Taper" protoplasts isolated in ultrapure water $(21.6 \mathrm{U} / \mathrm{min} / \mathrm{g}$ f.w.) - Figure 1. For "Taper," however, differences in POD activity were not as high as in the case of protoplasts isolated from "Lord."

Radical scavenging activity. In protoplasts obtained during isolation in CPW salt solution, the total antioxidant activity was the highest in all tested genotypes and is expressed as $375.8-701.8$ and $207.3-341.7 \mathrm{mg}$ DPPH scavenged by $1 \mathrm{~g}$ f.w. of lupine and grass pea protoplasts, respectively (Fig. 2). In contrast, isolation in ultrapure water and $\mathrm{C}$ solution resulted in a reduced 


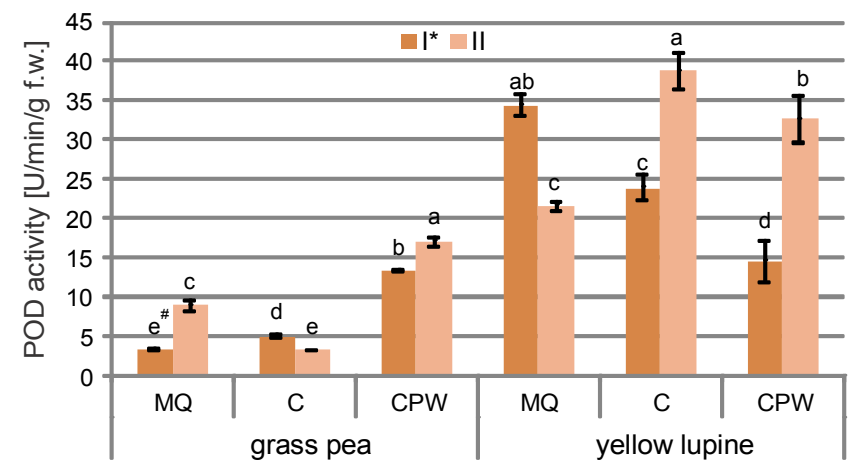

*grass pea I - "Derek", II - "Krab"; yellow lupine I - "Lord", II - "Taper"; " different letters - significant difference at $P \leq 0.05$ within one species

Fig. 1. The effect of solution type on peroxidase activity (U/min/g f.w.) of grass pea and yellow lupine protoplasts

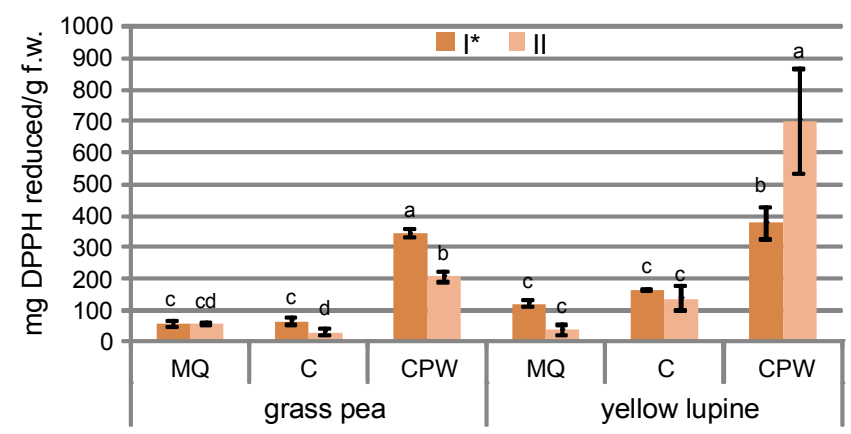

*grass pea I - "Derek", II - "Krab"; yellow lupine I - "Lord", II - "Taper"; different letters - significant difference at $P \leq 0.05$ within one species

Fig. 2. The effect of solution type on scavenging activity expressed as mg DPPH reduced/g f.w. of grass pea and yellow lupine protoplasts

radical scavenging activity in protoplasts of both legumes. In lupine, the radical scavenging activity ranged from 37.1 to $118 \mathrm{mg}$ of reduced DPPH in protoplasts isolated in ultrapure water and from 136.4 to $163.9 \mathrm{mg}$ of reduced DPPH in protoplasts isolated in $\mathrm{C}$ solution. In grass pea, after the isolation in ultrapure water, the radical scavenging ability of protoplasts ranged from 54.4 to $58.2 \mathrm{mg}$ of reduced DPPH, while in protoplasts isolated in C solution, it ranged from 29.4 to $62.8 \mathrm{mg}$ (Fig. 2).

\section{Discussion}

In our experiment, protoplasts were isolated in three different solutions containing various proportions of inorganic and organic compounds. Ultrapure water was used to provide isolation environment deprived of addi- tional substances. CPW salt solution, elaborated by Frearson et al. (1973), contains inorganic salts, while C solution is supplemented with several organic compounds, including polyvinylpyrrolidone and casein hydrolyzate. The results revealed that different isolation conditions caused different reactions of the antioxidant system in protoplasts. The question arises, whether an increase in the level of antioxidant efficiency (e.g., enzyme activity, phenolic compound accumulation) indicates a reaction on the stronger stress encountered during isolation, or rather a more responsive antioxidant system of protoplasts tested, to oxidative stress. It has been reported that during enzymatic digestion of plant tissue, ROS are produced, especially if macerating enzymes are used (Ishii, 1988; Papadakis et al., 2001). However, there is no information on the effect of the solvent type used to prepare enzymatic mixture.

Our results indicated that in protoplasts isolated both in pure water and solution rich in inorganic and organic compounds, the overall antioxidant activity was low. Although diverse plant material was used in this study (two recalcitrant species, two different types of explants as the sources of protoplasts) and a diverse isolation procedures were applied (different enzymes and incubation time), similar tendencies in the antioxidative response were observed. The activity and levels of chosen elements of antioxidant system were usually the highest in protoplasts isolated in CPW salt solution, which is commonly exploited in protoplast isolation protocols. CPW salt solution contains inorganic ions that play a role in plasma membrane stabilization and, as revealed by our study, induce, in some way, the antioxidant machinery of the cell. In turn, a high activity of antioxidant system is most probably crucial for the development of protoplasts in culture as well as for the regeneration capacity of protoplasts (Siminis et al., 1993, 1994; Xu et al., 2013).

Phenolic compounds are considered a part of an antioxidant network of the cell as they possess a high ability to scavenge toxic radicals and inactivate them without leading to further oxidative reactions (Grace, 2005). Flavonoids and phenolic acids are especially active in cell protection from lipid peroxidation (Terao et al., 1994). This unfavorable process occurs during the protoplast isolation and significantly reduces protoplast viability and also contributes to their recalcitrance (Cutler et al., 1989; Kapur et al., 1993; Xu et al., 2013). The high pro- 
portion of phenolic compounds in legume protoplasts isolated in $\mathrm{CPW}$ supports the idea that components of this solution may stimulate protoplasts to the antioxidant response to oxidative stress during isolation. On the contrary, polyvinylpyrrolidone (PVP) present in the $\mathrm{C}$ solution is not only known to complex phenolic compounds, but it is also able to complex other low molecular substances (e.g. salt impurities used for solutions) (Haaf et al., 1985) that could be an additional stress factor during isolation. Hence, the presence of PVP in C solution may result in lower stress during isolation and consequently reduce the production of phenolic compounds. In addition, our results revealed a low level of phenolics in protoplasts isolated in ultrapure water. This may indicate that the mineral salts included in the solutions may create stress conditions that stimulate protoplasts to activate antioxidant system.

However, to reliably assess which solution has the optimal impact for protoplast survivability and viability, it is necessary to verify how antioxidant system is functioning during protoplast cultivation. Variations in activity of antioxidant network may indicate on different regeneration potential (cell wall resynthesis, ability to divide) of cultured protoplasts.

Moreover, in our study, the activity of radical scavenging system was the highest in protoplasts isolated in $\mathrm{CPW}$ salt solution. Interestingly, these results complement the results concerning the level of phenolic compounds in protoplasts. Intensified synthesis of phenolics in protoplasts may result from increased oxidative stress and thus may support the thesis that phenolic compounds play an antioxidative role during protoplast isolation. On the contrary, there is also possibility that synthesized phenols are components of newly reconstructed cell walls. This process could be promoted by the magnesium ions present in CPW salt solution.

Studies on cultured protoplasts have revealed that POD activity is constant during the first days of culture and then either increases in regenerating protoplasts or decreases in those non-regenerating (de Marco and Roubelakis-Angelakis, 1996). Moreover, POD activity was found to be significantly higher in dividing protoplasts than in non-dividing (Xu et al., 2013). POD activity could also be considered a predictor of hydrogen peroxide accumulation during isolation and culture (Papadakis and Roubelakis-Angelakis, 2002). In this respect, the accumulation of ROS could be related to reprogramming of the developmental pathway of the cell (Jones and Smirnoff, 2005). A very high POD activity determined in our study in yellow lupine protoplasts may indicate intensive accumulation of ROS during isolation. A different response of the examined cultivars to isolation stress could be attributed to their different susceptibility to ROS accumulation and morphogenic ability. However, this has to be verified in a study conducted on cultured protoplasts. Nevertheless, interpretation of the POD data should be made with some caution because this enzyme is involved in a number of processes apart from detoxication during oxidative stress, such as lignin biosynthesis or production of quinones (Cazaux and d'Auzac, 1995).

The obtained results have confirmed that the isolation environment affects the level and activity of selected components belonging to a cell antioxidant system in legume protoplasts. It is an important piece of information in relation to recalcitrance of these plants in in vitro conditions because events occurring at the stage of isolation may affect further development of protoplasts in the culture. Priorities for the future studies involve 1) the analysis of the antioxidative network during the protoplast culture and 2) revelation of the relationships between the antioxidative response and the mitotic ability and regenerability of cultured protoplasts.

\section{Acknowledgments}

This research was financed by Ministry of Science and Higher Education of Republic of Poland (DS 3500).

\section{References}

Augustynowicz J., Długosz-Grochowska O.G., Kostecka-Gugała A.M., Leja M., Kruczek M.K., Swiderski A. (2014) Callitriche cophocarpa - a new rich source of active phenolic compounds. Cent. Eur. J. Chem. 12(4): 519-527.

Babaoglu M. (2000) Protoplast isolation in lupin (Lupinus mutabilis Sweet): determination of optimum explant sources and isolation conditions. Turk. J. Bot. 24(3): 177-186.

Cazaux E., d'Auzac J. (1995) Explanation for the lack of division of protoplasts from stems of rubber-tree (Hevea brasiliensis). Plant Cell Tiss. Org. Cult. 41(3): 211-219.

Cutler A.J., Saleem M., Coffey M.A., Loewen M.K. (1989) Role of oxidative stress in cereal protoplast recalcitrance. Plant Cell Tiss. Org. Cult. 18(1): 113-127.

de Marco A., Roubelakis-Angelakis K.A. (1996) The complexity of enzymic control of hydrogen peroxide concentration may affect the regeneration potential of plant protoplasts. Plant Physiol. 110(1): 137-145.

Durieu P., Ochatt S.J. (2000) Efficient intergeneric fusion of pea (Pisum sativum L.) and grass pea (Lathyrus sativus L.) protoplasts. J. Exp. Bot. 51: 1237-1242. 
Frearson E.M., Power J.B., Cocking E.C. (1973) The isolation, culture and regeneration of Petunia leaf protoplasts. Dev. Biol. 33: 130-137.

Fukumoto L., Mazza G. (2000) Assessing antioxidant and prooxidant activities of phenolic compounds. J. Agric. Food Chem. 48(8): 3597-3604.

Grace S.C. (2005) Phenolic as antioxidants. In: Antioxidants and reactive oxygen species in plants. Ed. N. Smirnoff. Oxford: Blackwell Publishing: 141- 168.

Haaf F., Sanner A., Straub F. (1985) Polymers of N-vinylpyrrolidone: synthesis, characterization and uses. Polymer J. 17(1): 143-152.

Hahne G., Lörz H. (1988) Release of phytotoxic factors from plant cell walls during protoplast isolation. J. Plant Physiol. 132(3): 345-350.

Hou S.W., Jia J.F. (2004) Plant regeneration from protoplasts isolated from embryogenic calli of the forage legume Astragalus melilotoides Pall. Plant Cell Rep. 22: 741-746.

Ishii S. (1987) Generation of active oxygen species during enzymatic isolation of protoplasts from oat leaves. In Vitro Cell Dev. Biol. 23(9): 653-658.

Ishii S. (1988) Factors influencing protoplast viability of suspension-cultured rice cells during isolation process. Plant Physiol. 88(1): 26-29.

Jones M.A., Smirnoff N. (2005) Reactive oxygen species in plant development and pathogen defense. In: Antioxidants and reactive oxygen species in plants. Ed. N. Smirnoff. Oxford: Blackwell Publishing: 197-214.

Kapur R., Saleem M., Harvey B.L., Cutler A.J. (1993) Oxidative metabolism and protoplast culture. In Vitro Cell. Dev. Biol. 29(4): 200-206.

Kuchuk N., Griga M., Kosturkova G., Ilieva-Stoilova M. (2000) Biotechnology. In: Carbohydrates in grain legume seeds: improving nutritional quality and agronomic characteristics. Ed. Hedley C.L. Wallingford: CABI Publishing: 145-207.

Lück H. (1962) Methoden der enzymatischen analyse. Verlag Chemie GmbH, Weinheim.

Menczel L., Nagy F., Kiss Zs.R., Maliga P. (1981) Streptomycin resistant and sensitive somatic hybrids of Nicotiana tabacum + Nicotiana knightiana: correlation of resistance to N. tabacum plastids. Theor. Appl. Genet. 59: 191-195.

Meyer Y., Chartier Y., Grosset J., Marty L., Brugidou C., Marinho P., River R. (1993) Gene expression in mesophyll protoplasts. In: Morphogenesis in plants. Molecular approaches. Ed. Roubelakis-Angelakis K.A., Van K.T.T. New York: Springer: 221-236.

Murashige T., Skoog F. (1962) A revised medium for rapid growth and bioassays with tobacco tissue cultures. Physiol. Plant. 15: 473-497.

Ochatt S., Durieu P., Jacas L., Pontécaille C. (2001) Protoplast, cell and tissue cultures for the biotechnological breeding of grass pea (Lathyrus sativus L.). Lathyr. Lathyrism Newslett. 2(1): 35-38.

Papadakis A.K., Roubelakis-Angelakis K.A. (2002) Oxidative stress could be responsible for the recalcitrance of plant protoplasts. Plant Physiol. Biochem. 40(6): 549-559.
Papadakis A.K., Siminis C.I., Roubelakis-Angelakis K.A. (2001) Reduced activity of antioxidant machinery is correlated with suppression of totipotency in plant protoplasts. Plant Physiol. 126(1): 434-444.

Pekkarinen S.S., Stöckmann H., Schwarz K., Marina Heinonen I., Hopia A.I. (1999) Antioxidant activity and partitioning of phenolic acids in bulk and emulsified methyl linoleate. J. Agric. Food Chem., 47: 3036-3043.

Pratap A., Choudhary A.K., Kumar J. (2010) In vitro techniques towards genetic enhancement of food legumes a review. J. Food Legumes 23: 169-185.

Roubelakis-Angelakis K.A. (1993) An assessment of possible factors contributing quercetin on lipid peroxidation in phospholipid bilayers. Arch. Biochem. Biophys. 308: 278284.

Rybczyński J.J. (1997) Plant regeneration from highly embryogenic callus, cell suspension and protoplast cultures of Trifolium fragiferum. Plant Cell Tiss. Org. Cult. 51: 159-170.

Schafer-Menuhr A. (1991) Regeneration of shoots from protoplasts of lupins. Lupin Newslett. 14: 42-44.

Siminis C.I., Kanellis A.K., Roubelakis Angelakis K.A. (1993) Differences in protein synthesis and peroxidase isoenzymes between recalcitrant and regenerating protoplasts. Physiol. Plant. 87(3): 263-270.

Siminis C.I., Kanellis A.K., Roubelakis-Angelakis K.A. (1994) Catalase is differentially expressed in dividing and nondividing protoplasts. Plant Physiol. 105(4): 1375-1383.

Sinha A., Caligari P.D.S. (2009) A breakthrough in lupin biotechnology: prolific protocolonisation in recalcitrant white lupin (Lupinus albus) triggered by bovine serum albumin. Ann. Appl. Biol. 154(2): 183-194.

Sonntag K., Ruge-Wehling B., Wehling P. (2009) Protoplast isolation and culture for somatic hybridization of Lupinus angustifolius and L. subcarnosus. Plant Cell Tiss. Org. Cult. 96(3): 297-305.

Święcicki W., Rybczyński J.J., Święcicki W.K. (2000) Domestication and genetics of the yellow lupin (Lupinus luteus L.) and the biotechnological improvement of lupins. J. Appl. Genet. 41: 11-34.

Terao J., Piskuli M., Yao Q. (1994) Protective effect of epicatechin, epicatechin gallate, and to recalcitrance of plant protoplasts. In: Morphogenesis in plants. Molecular approaches. Ed. Roubelakis-Angelakis K.A., Van K.T.T. New York: Springer: 201-219.

Wiszniewska A., Pindel A. (2009) Improvement in Lupinus luteus (Fabaceae) protoplast cultures - stimulatory effect of agarose embedding and chemical nursing on protoplast divisions. Austral. J. Bot. 57: 502-511.

Wiszniewska A., Piwowarczyk B. (2014) Studies on cell wall regeneration in protoplast culture of legumes - the effect of organic medium additives on cell wall components. Czech J. Genet. Plant Breed. 50(2): 84-91.

Wiszniewska A., Piwowarczyk B., Pindel A. (2012) The influence of isolation stress on the (re)organization of cell walls in protoplasts of in vitro recalcitrant plants. BioTechnologia. 93(2): 102-108. 
Xu X., Xie G., He L., Zhang J., Xu X., Qian R., Liang G., Liu J.H. (2013) Differences in oxidative stress, antioxidant systems, and microscopic analysis between regenerating callus-derived protoplasts and recalcitrant leaf mesophyllderived protoplasts of Citrus reticulata Blanco. Plant Cell Tiss. Org. Cult. 114(2): 161-169.
Zafar Y., Nenz E., Damiani F., Pupilli F., Arcioni S. (1995) Plant regeneration from ex plant and protoplast derived calluses of Medicago littoralis. Plant Cell Tiss. Org. Cult. 41: 41-48. 